\title{
EDITORIAL DA REVISTA e-CURRICULUM
}

\author{
Edição 19 (2) abril/junho 2021
}

\section{AINDA NA PANDEMIA, O ESFORÇO DE PRODUÇÃO E DIVULGAÇÃO DO CONHECIMENTO CIENTÍFICO}

$\mathrm{Na}$ edição deste número, a revista e-Curriculum empenhou-se em um período conturbado da vida nacional, com o número constrangedor de óbitos - a perda de mais de quinhentas mil vidas pela Covid-19. O Brasil permanece no epicentro da pandemia e, pelos prognósticos, está ameaçado de ingressar em uma terceira onda de contágio e elevar, assim, muito o número de óbitos.

Desse modo, está dentre os países com maior índice de mortes causadas pelo surto pandêmico. Esse fato infausto veio acompanhado de denúncias sobre a incúria e a incompetência, além de corrupção das autoridades sanitárias na gestão sanitária da Covid-19. Foram denunciados pela imprensa como agentes incompetentes para estabelecer uma estratégia de vacinação célere, a fim de debelar uma das maiores catástrofes sanitárias do Brasil e do mundo contemporâneo.

A pandemia afetou todos os aspectos do nosso modo de vida: nossos hábitos e nossas certezas; alterou, profundamente, nossas atividades cotidianas, prejudicou projetos, reconfigurou as relações sociais, interrompeu a vida cultural e conturbou as atividades cientificas, dentre as quais, a publicação de revistas. Ela expos, de forma contundente, a vulnerabilidade da vida pessoal e do convívio social, e revelou a impotência frente aos dilemas que exigem união política e competência científica.

Essa crise sanitária e humanitária tornou-se, pois, um problema nacional: a revelação crescente das pessoas infectadas e mortas, anunciadas pela imprensa, associada a um clima de incerteza e dúvidas sobre o futuro da vida, promovidas pela retórica presidencial, e secundadas pelas instâncias governamentais, fomentaram um clima de hesitação vacinal e sanitária, além de dúvidas sobre a competência política na gestão da pandemia. Muitos/as brasileiros/as viramse expostos aos dramas e dores pelos riscos a que se sentiram deixados pelas autoridades 
políticas. Nesse clima conturbado, a revista concentrou todos os esforços para manter a pontualidade aprazada deste seu novo número.

Nesta edição, segunda de 2021, são publicados dezoito artigos, oriundos da demanda espontânea de diferentes regiões do Brasil. Os artigos tratam de temáticas do currículo em diferentes áreas do conhecimento e níveis de ensino, bem como da formação de professores; evidenciam variadas metodologias e estão ancorados em um leque de diferentes linhas teóricas.

Luciano Gamez e Viviane Cristina Marques apoiaram sua pesquisa no Psicodrama Clássico, proposto por Moreno, e nas reinterpretações deste para o contexto educacional, conduzidos por Maria Alicia Romaña. A base teórica dessa investigação trabalhou, também, com conceitos de Paulo Freire e Vygotsky. Utilizando a técnica de análise do discurso de narrativas individuais e coletivas com base em vivências psicodramáticas, os autores concluem que o Psicodrama Pedagógico possibilita práticas pedagógicas inovadoras no contexto do ensino superior online.

O objeto de estudo do artigo de Sheilla Silva da Conceição, Gabriel Augustus de Aquino Dias Leão e Henrique Nou Schneider é a gamificação na perspectiva da construção interdisciplinar e colaborativa do conhecimento. Por meio de um relato de experiência realizada no componente curricular informática educativa, os autores desenvolveram uma pesquisa do tipo participante-intervenção, com apoio nos estudos de Thiollent. As conclusões demonstram que as propostas de gamificação dos alunos e seus relatos em um formulário digital reforçam o caráter interdisciplinar do componente curricular e confirmam esse processo como uma experiência significativa.

O artigo de Edson José Neves Júnior e Jaqueline Maissiat abarca dois objetivos. Acerca do primeiro, por meio da discussão sobre a definição conceitual-normativa da dimensão da extensão do ensino superior, os autores concluem que essa é abrangente, polissêmica e, consideravelmente, neutra. Já sobre o segundo objetivo, analisar como a creditação da extensão tem sido implementada nas Instituições de Ensino Superior do país desde sua regulamentação nacional em 2018. Nota-se, por um lado, modelos de curricularização com abordagens transformadoras e, por outro lado, a existência de modelos que apenas procuram adaptar a pressão por alteração.

O trabalho de Dayane Santos Silva e Rosa Maria Feiteiro Cavalari enfoca a temática ambiental nos cursos de Ciências Biológicas em uma universidade paraibana. A partir da análise 
documental, as autoras realizaram um estudo de caso e observaram que a temática ambiental vinculada ao contexto do semiárido está presente na estrutura curricular dos cursos em foco e que o processo de Ambientalização Curricular ultrapassa as questões curriculares e, também, deve abordar a formação de professores tal qual a relação desses com o contexto em que estão incluídos.

Em ritmo de carnaval, Danilo Araujo de Oliveira, Anderson Ferrari e Carla Char trazem o samba-enredo da Mangueira, de 2019, para problematizar o conceito foulcatiano de heterotopias nos espaços curriculares. Com o objetivo de discutir as possibilidades de um currículo que ultrapasse a linha do instituído, os autores argumentam que o samba-enredo em questão promove a reflexão acerca das possibilidades de contraespaços e alargarmento do território curricular para que nele caibam modos de vidas considerados invivíveis. Quando utilizamos o samba e o desfile para problematizar as heterotopias no currículo, vemo-nos implicados na política das subjetividades e nos outros espaços para além da Sapucaí, aqueles em que o desfile pode se desdobrar em novas construções e (des)continuidades.

Outro artigo que se ampara na teoria de Michel Foucault é apresentado pelo autor Mário Luiz Ferrari Nunes que, por meio de entrevistas narrativas que investigaram o currículo de um curso de Educação Física, utiliza a noção de governamentalidade para discutir como a globalização e a hegemonia neoliberal com vistas ao controle das populações incidem na formação da identidade docente e em sua prática pedagógica. De acordo com as conclusões do trabalho, argumenta-se que o dispositivo currículo não permite que o docente perceba a influência dos discursos que favorecem a governamentalidade neoliberal em sua prática pedagógica.

O currículo do curso superior de Educação Física também é objeto de investigação da pesquisa de Alfredo Cesar Antunes. O autor investigou a produção acadêmica na área com foco na Inovação Curricular e identificou os seguintes fatores: o contexto em que o ensino ocorre, o status científico e político da área, os conteúdos a serem desenvolvidos e os procedimentos de ensino. Ao final, o estudo conclui que são necessárias outras pesquisas que identifiquem ações e propostas de inovação curricular, além de maior atenção com o tema no que se refere à inovação curricular, na graduação.

Revista e-Curriculum, São Paulo, v. 19, n. 2, p. 536-542, abr./jun. 2021 
Ao utilizar a metodologia da revisão integrativa amparada no paradigma da inclusão, no currículo narrativo e no design universal para aprendizagem (DUA), as pesquisadoras Elizabete Cristina Costa-Renders, Maria Aparecida do Nascimento Gonçalves e Marcela Herrera dos Santos procuram responder a seguinte questão: como os três princípios do DUA podem contribuir para a abordagem inclusiva em escolas brasileiras? Os resultados evidenciam a maior narratividade, abertura e flexibilidade curricular, fatos que impactam no grau de influência dos estudantes no currículo e possibilitam maior engajamento dos mesmos no processo.

A temática da educação de surdos também está presente nesta edição. Procurando investigar as tendências na produção científica brasileira sobre a internacionalização da área, Indiamaris Pereira e Paulo Roberto Senhem realizaram uma revisão sistemática dos estudos dessa área, concluindo que a internacionalização na educação de surdos é uma lacuna a ser exploradas em pesquisas futuras.

Por meio de pesquisa bibliográfica e de uma visita técnica a uma escola em Israel, Armgard Lutz analisa a reinvenção da escola com base na justiça curricular e nos estudos culturais. Autores como Connell (1995), Thurler (2001), Calvo (2016), Prensky (2017), Tough (2017) sustentam a urgência da inovação diante das mudanças na sociedade e no modo de ser da nova geração, conectada com os meios tecnológicos. O estudo discute a urgência de inovação e o encantamento com os modelos 3.0 sem se furtar de questionar os vínculos neoliberais da educação por competências que tais modelos possuem. Salienta que a complexidade da formação continuada de professores comprometida com a justiça curricular possibilita o desvelamento das desigualdades sociais e educacionais e promove resistências coletivas.

A disciplina online de metodologia científica de uma universidade privada do Rio de Janeiro é o contexto da pesquisa de Natalia de Lacerda Gil, Caterine Vila Fagundes e Katia Cristian Puente Muniz, que realizaram um estudo ex-post-facto de caráter descritivo e exploratório, para apresentar um modelo didático para a construção da escrita acadêmica e, então, verificá-lo. As conclusões das autoras apontam para a efetividade de um modelo que se desloque da racionalidade técnica para a racionalidade prática nas práticas pedagógicas que concernem à escrita acadêmica.

No artigo de Maria Idalina Krause de Campos, Sandra Mara Corazza e Marina dos Reis, os métodos espiritográfico e sonhográfico são utilizados na educação da diferença em uma prática de aula-tradução. De acordo com a proposição das autoras, pesquisas que se dão por 
meio de leitura escrita (ou escrileituras, na terminologia utilizada por elas) efetivam novas possibilidades de linguagem curricular. As autoras concluem que uma aula-tradução se afirma como uma poética disparadora de sentidos que para uma didática da invenção, afeita aos sonhos e às aventuras do intelecto na agoridade do magistério contemporâneo.

As pesquisas curriculares relacionadas à área da saúde marcam presença nesta edição. Simone Beatriz Pedrozo Viana, Regina Célia Linhares Hostins e Juan José Beunza desenvolvem um estudo pautado na análise de literatura sobre a Educação Interprofissional (EIP) no ensino de graduação em saúde no Brasil, tomando como referencial os pressupostos teóricos de Barr, Reeves; D’amour; Peduzzi e Canadian Interprofessional Health Collaborativ. Os autores concluíram que as iniciativas de EIP são recentes e, desse modo, carecem de sistematização quanto ao modelo a ser utilizado.

Outro trabalho que se insere na área da saúde é o artigo das pesquisadoras Márcia Maria Ribera Lopes Spessoto e Giselle Cristina Martins Real. Por meio de análise documental das matrizes curriculares de cursos de Licenciatura e Bacharelado em Enfermagem de Universidades Públicas Estaduais, verificaram que tais cursos vêm mantendo a organização curricular associada entre os graus, independentemente das orientações de separação do MEC. Destaca-se a prática como componente curricular e a realização fracionada do estágio curricular supervisionado de licenciatura que, a princípio, é direcionado à educação básica e, posteriormente, à educação profissional técnica de nível médio, abordando diferentes possibilidades de inserção do enfermeiro licenciado.

O trabalho de Ana Paula Salvatori e Allan Henrique Gomes tem como objetivo analisar um percurso de pesquisas e práticas de um curso de psicologia realizadas no Sistema Único de Assistência Social (SUAS) de um município do sul do Brasil. Por meio de uma pesquisa documental, com perspectiva sócio-histórica, os autores analisaram trabalhos de conclusão de curso e relatórios de estágio dos anos finais da graduação. Os resultados constataram a presença de elementos em construção da prática profissional na formação inicial e aproximações ao campo da desigualdade social no período que compreende a implantação e consolidação da Política Nacional de Assistência Social no país.

O artigo escrito por Ana Clédina Rodrigues Gomes e Valdineia Rodrigues Lima analisa a relação de Pesquisas na Pós-Graduação com as políticas curriculares e o ensino de matemática 
no Ensino Médio. $\mathrm{O}$ estudo utilizou a pesquisa bibliográfica com abordagem qualitativa. $\mathrm{O}$ referencial teórico tomou como referência Lopes (2004, 2005), Lopes e Macedo (2011), Mainardes et al. (2011). Os resultados demonstraram que as pesquisas sofrem influências das políticas educacionais. A pesquisa apontou também que que as produções sobre o ensino de matemática precisam ser ampliadas e a área de Educação Matemática pode contribuir com investigações sobre questões mais abrangentes, possibilitando estudos que considerem também as políticas curriculares.

Analisando a realidade curricular de um curso técnico integrado em química, Karla Rodrigues Mota e Cláudia Helena dos Santos Araújo investigam o Projeto Pedagógico do curso em questão e, também, 50 Planos de Ensino Anuais a fim de compreender como os elementos pesquisa, contextualização, interdisciplinaridade e flexibilidade apresentam-se nos documentos. Conclui-se que, embora o currículo do curso apresente uma forma integrada, a disciplinarização dos conteúdos predomina no planejamento pedagógico. Desse modo, a realidade é apresentada ao estudante de forma fragmentada, ofuscando a compreensão dos fenômenos e dificultando a emancipação contra-hegemônica desse sujeito.

Finalizamos esta edição com o artigo de Veronica Domingues Almeida e Maria Roseli Gomes Brito de Sá, que discorre sobre as tessituras curriculares de um Mestrado Profissional em Educação. As autoras apresentam a proposta do curso, com ênfase na centralidade de pesquisas sobre e no currículo como concretização de Investigações em Campo Piloto. A argumentação realizada enfatiza a dimensão inovante do curso, que privilegia a processualidade, a organização em rede, a heterogeneidade e a diferença como princípios não colonizadores e por arquitetar inovações instituintes, fundadas de modo colaborativo e abertas à diversidade e à heterogeneidade dos processos educativos de redes públicas de Educação Básica.

A Revista e-Curriculum agradece, mais uma vez, todo o conjunto de colaboradores que tornaram possível esta edição. Dentre eles, destacam-se os autores, pareceristas, membros do conselho editorial e do suporte técnico institucional que não pouparam esforços para produzir, e divulgar o conhecimento científico, tendo em vista ampliar a pesquisa no campo da educação e, em especial, na área do currículo.

O conselho editorial da Revista reconhece que o momento atual é extremamente difícil, na realidade brasileira e no mundo, gerando tristeza e desespero. Nessas condições, o trabalho 
Programa de Pós-Graduação em Educação: Currículo

tem se tornado árduo e, até mesmo, desanimador. Todavia, temos que resistir e buscar, com esperança ativa, a construção de um outro mundo possível, mais democrático, com saúde para todos e todas, e com justiça social.

Antonio Chizzotti

Ana Maria Saul

Junho de 2021 